\title{
New Tubular Ceramic Membranes from Natural Moroccan Clay for Microfiltration Application
}

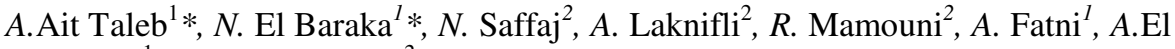 \\ Hammadi $^{1}$ and $N$. El Qacimi ${ }^{2}$ \\ ${ }^{1}$ Faculty polydisciplinaire,University Ibn Zohr, BP 271, Taroudant, Morocco, . \\ ${ }^{2}$ Faculty polydisciplinaire,University Ibn Zohr, BP 638, Ouarzazate, Morocco, \\ ${ }^{3}$ Faculty of Sciences,University Ibn Zohr, BP 8106, Cite Dakhla, Agadir, Morocco,
}

\begin{abstract}
This paper is devoted the preparation of low cost microfiltration membranes using Moroccan clay powder. The preparation of membrane was composed with two steps: First a macroporous tubular support with a pore diameter $10 \mu \mathrm{m}$ and porosity $43 \%$. Secondly a microfiltration layer was performed by the slip casting method. A deflocculated slip was obtained by mixing mineral powder of $\mathrm{ZrO} 2$, PVA (polyvinyl alcohol) and water, after drying at room temperature for $24 \mathrm{~h}$, the microfiltration layer was heated to $800^{\circ} \mathrm{C}$ for consolidation. Scanning electron microscopy observation showed homogeneous layers without cracks with an average pore diameter of $0.19 \mu \mathrm{m}$ for the active layer. Water permeability obtained is about 841 L/h.m2.bar. The membranes have been tested to cleaning of colored wastewater.

Keywords: Wastewater treatment; Ceramic membrane; Tubular support; Microfiltration; Clay.
\end{abstract}

\footnotetext{
* Corresponding author: a.aittaleb@uiz.ac.ma / n.elbaraka@uiz.ac.ma
} 


\section{Introduction}

In the last 10 years the separation by the use of membranes ceramic has rapid increasing. The membrane separation technologies have found a use in various fields: chemistry, food, urbanization; industrial, agricultural and domestic wastewater treatment [1]. For environmental and economic consideration, numerous researches have been focalized to development of new type of low inorganic membranes, which present good chemical stability, favorable mechanical strength, good antimicrobial ability and high separation efficiency.

Generally, commercial ceramic membranes are prepared from amphoteric oxides such as alumina, titania, zirconia [2-6], and sometime also with carbone which is in expensive precursor to fabricate the membrane, Yachino 2005 [7]. To avoid the issue of membrane cost, resent research in the fabrication of inorganic membrane is focused towards of utilization of cheaper raw materiels.

A lot of local natural materials were used for membrane preparation, in our laboratory, such as natural and artificial clays like kaolinite, cordierite [8-10], perlite [11] and animal bon [12] to prepare support which were coated with $\mathrm{ZnAl} 2 \mathrm{O} 4-\mathrm{TiO} 2$ ultrafiltration layer, Rakib et al. [13] who developed the microfiltration membranes with natural clays, Elmodden et al. [14] and Weir et al. [15]. In our previous studies, we developed a new ceramic support for microfiltration membrane, with flat disk configuration, based on natural Moroccan clay [16]. The support was elaborated by extrusion of the plastic paste and sintering at $800{ }^{\circ} \mathrm{C}$. The structural properties of clay support are satisfying in terms of porosity and pore diameter. It presents a well chemical resistance in acidic and basic medium.

In order to reduce energy costs of membranes we have developed in this present work a new microfiltration monotubular membranes prepared from natural clay.

The choice of natural clay is mostly due on its abundance in Morocco, its low cost than other commercial powders, to its mechanical resistance, their chemical and thermal stability [17-18].

In the current work reports the fabrication of tubular macro-porous clay support by extrusion followed by sintering, the goal of this work is now focused on the use of $\mathrm{ZrO} 2$ as possible intermediate layer material for microfiltration membrane.

In particular, the preparation of microfiltration membrane made with natural Moroccan clay, will be presented successively and application of these membranes for the clarification of synthetic solutions the methylene bleu.

\section{Expérimental}

\subsection{Clay powder}

Natural clay was collected from Ouled Taima at $40 \mathrm{Km}$ of Agadir, Morocco. The powder was crushed at $125 \mu \mathrm{m}$ with disc mills. The chemical composition of this powder is given in weight percentage (wt. \%) as follows : $43 \% \mathrm{Al} 2 \mathrm{O} 3,35 \% \mathrm{SiO} 2,15 \% \mathrm{Fe} 2 \mathrm{O} 3,3.5 \% \mathrm{Na} 2 \mathrm{O}$, $1.2 \% \mathrm{~K} 2 \mathrm{O}$ and $0.03 \% \mathrm{MnO}$, it reveals that the clay is essentially formed of alumina with silica [16]. 


\subsection{Elaboration of porous tubular supports}

For this study, the process to elaborate tubular support is similar like that used in our previous work to prepare flat disk support [16]. The plastic pastes are prepared from the clay powder at $125 \mu \mathrm{m}$ mixed with organic additive and water. Plasticizer and binder are required to prepare a paste with rheological properties allowing the chapping by extrusion. The optimal formulation of the paste after several test is: $81.7 \% \mathrm{w} / \mathrm{w}$ of clay, amidon $10 \%$ w/w (Amidon de maïs RG03408, Cerestar) as porosity agent, Methocel 4\% w/w (The Dow Chemical Company), cellulose derivative, as a plasticizer, Amijel 4\% w/w (Cplus 12072, Cerestar) as a binder and PEG $15000.3 \% \mathrm{w} / \mathrm{w}$ (Prolabo) as a binder. The mixture was aged ( $250 \mathrm{tr} / \mathrm{min}$ ) during $30 \mathrm{~min}$ in order to obtain a good homogeneity. After adding the water (32\% w/w of powders) and Zusoplast $0.24 \% \mathrm{w} / \mathrm{w}$ (Zschimmer and Schwartz), we pugging the mixture for $30 \mathrm{~min}$ and the paste is kept in a closed box for 2 days under high humidity to avoid premature drying and to ensure complete diffusion of the water and organic additives.

The tubular support is then obtained by extrusion of the prepared ceramic paste. After extrusion, the wet support is kept on rollers of filter paper to obtain a homogenous drying at room temperature. The extruded pieces were sintered at $800{ }^{\circ} \mathrm{C}$ in furnace (Figure 1). Process of the ceramic support preparation was discrebed in Figure 2.

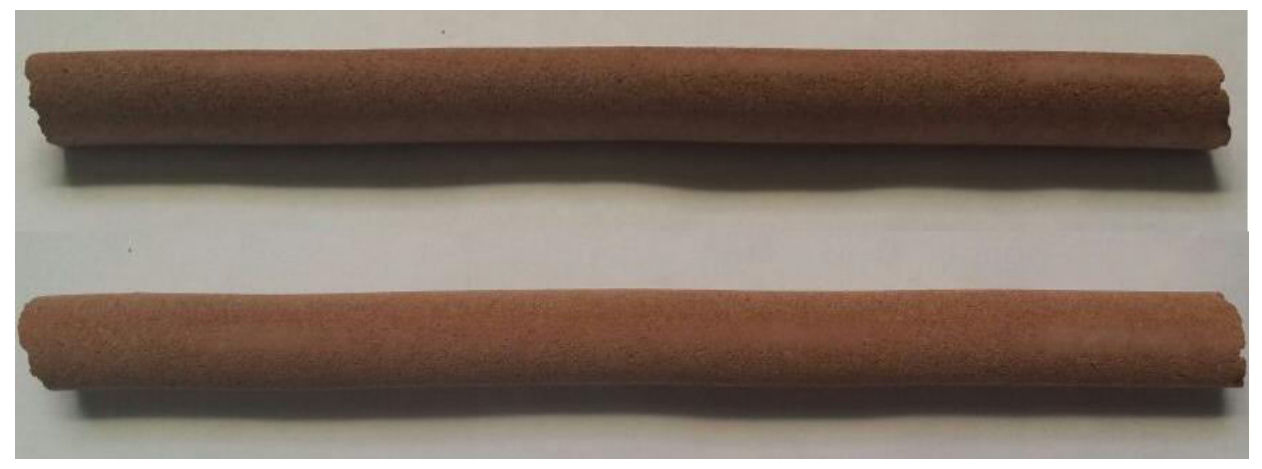

Fig. 1. A photograph of porous tubular ceramic supports. 


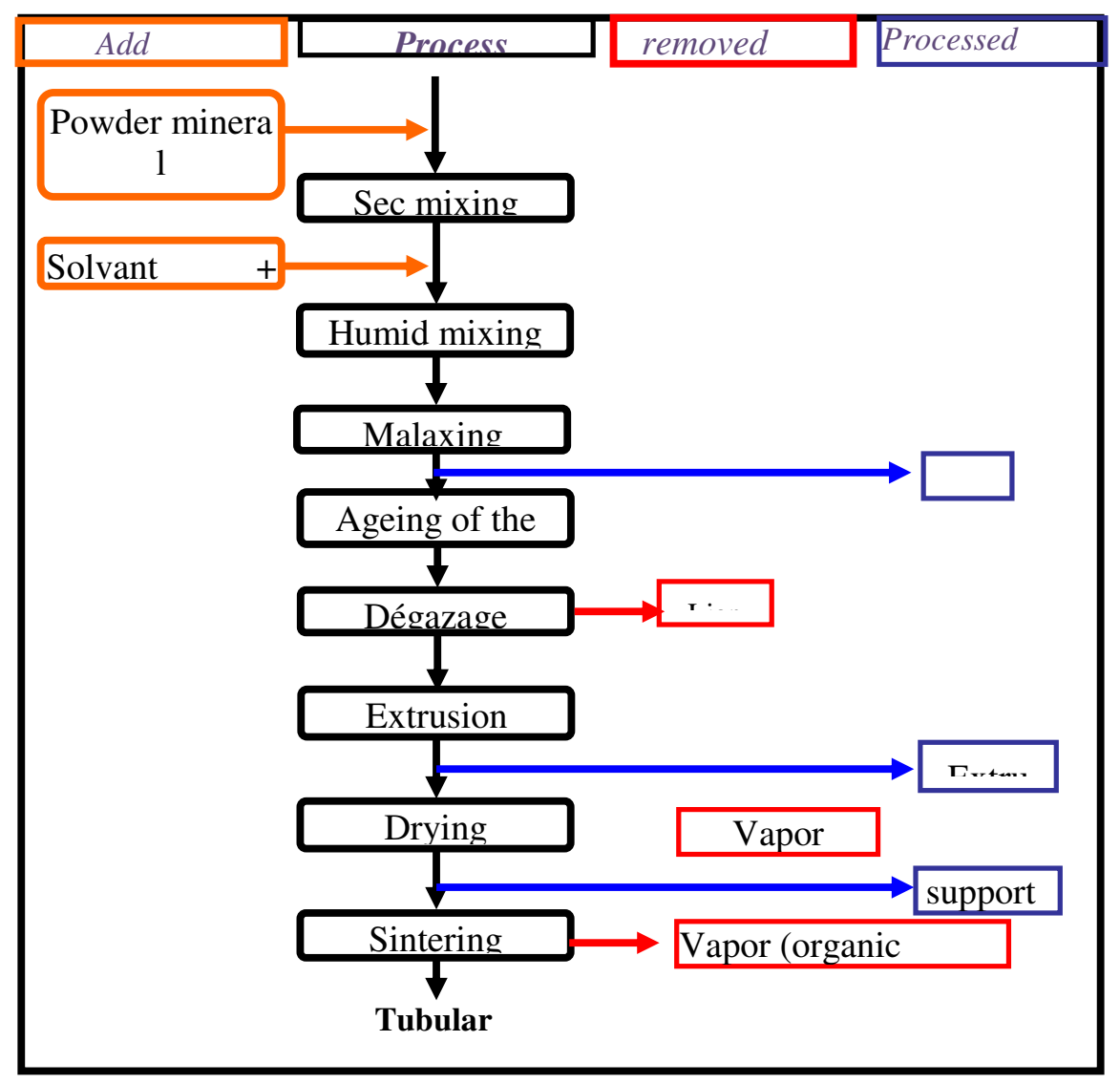

Fig. 2. Process of elaboration porous tubular suuport

\subsection{Development of microfiltration layer}

The microfiltration layer was obtain by slip casting (Figure 3 ) by means of a deflocculated suspension which is prepared by mixing $10 \mathrm{wt} \%$ of mineral powder $(\mathrm{ZrO} 2), 30 \mathrm{wt} \%$ of PVA (12 wt \% aqueous solution) and water with dispersant DOLAPIX PC 67 at $60 \%(0.2$ wt $\%$ aqueous solution). Dispersion of the apatite particles was achieved by applying ultrasonic agitation for $10 \mathrm{~min}$. The viscosity is an important parameter to determine the slip optimal composition.

The tubular support was coated with the $\mathrm{ZrO} 2$ dispersion, dried at room temperature and fired at a temperature of $800{ }^{\circ} \mathrm{C}$ for $2 \mathrm{~h}$. Total porous volume and pore size distribution are measured by mercury porosimetry. 


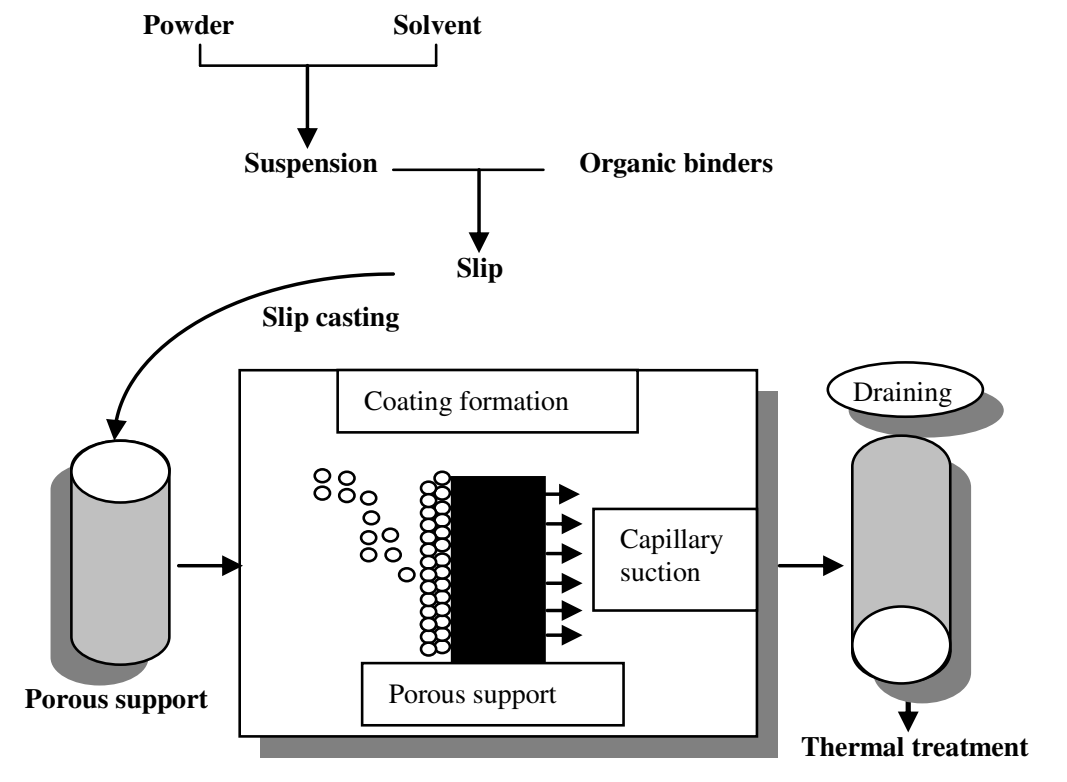

Fig. 3. Slip-casting process [19].

\subsection{Tests of filtrations}

Tangential filtration tests were performed on a laboratory scale filtration pilot using a recycling configuration (Figure 4). It was equipped with an adjustable out-flow pump, a thermostatic feed tank and a membrane module of $15 \mathrm{~cm}$ length. The filtration area developed by the membrane is $1.9 * 10-3 \mathrm{~m} 2$. A valve was used to control the pressure in the system, it varies between 0 and 2 bar. Membranes were conditioned by immersion in pure deionised water for a minimum of $24 \mathrm{~h}$ before the filtration tests.

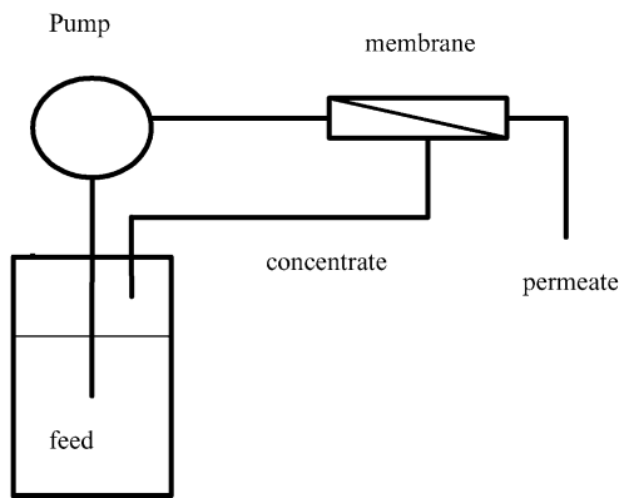

Fig. 4. Scheme of the pilot. 


\section{Results and discussion}

\subsection{Characterization of the support}

\section{1-1 Scanning electron micrograph}

The SEM micrograph reported on Figure 5 show the surface and the cross section view of the tubular support. SEM image show there is a good consolidation obtained at sintered temperature; the appearance of the sample surface is homogeneous and does not show defects.

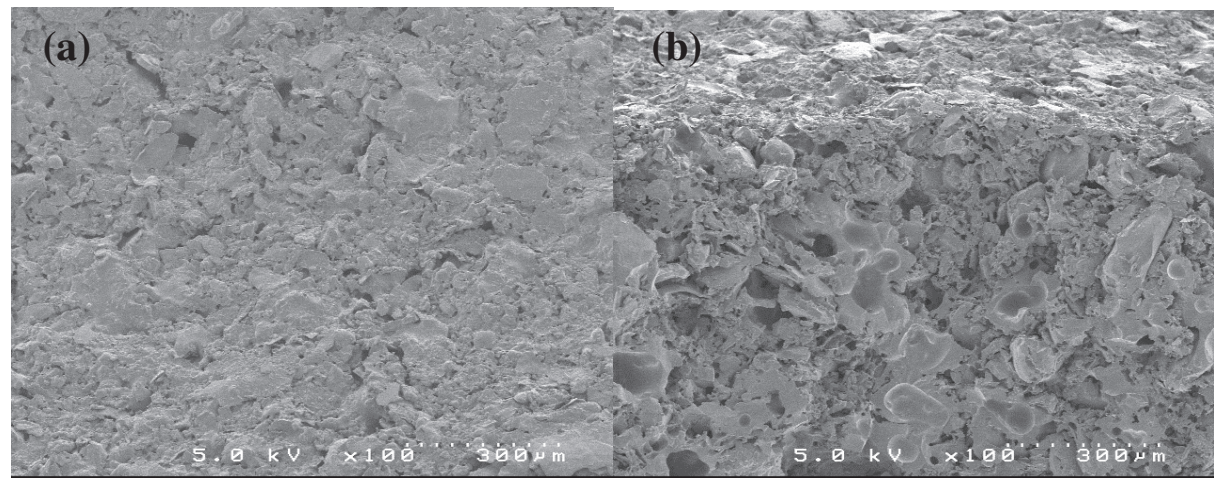

Fig. 5. Scanning electron micrographs of the support :(a) surface view.,(b) cross section view.

\section{2-1 Water permeability}

Water permeability is always a key factor on membrane applications, experiments show that the water flux depends on the applied pressure. The average support permeability determined using pure distilled water is $1926 \mathrm{~L} / \mathrm{h} \mathrm{m} 2$ bar (Figure 6).

The other characterizations of the support like the pore volume $\mathrm{Vp}$, the pore diameter $\mathrm{Dp}$, chemical resistance were detailed in our previous paper [Me].

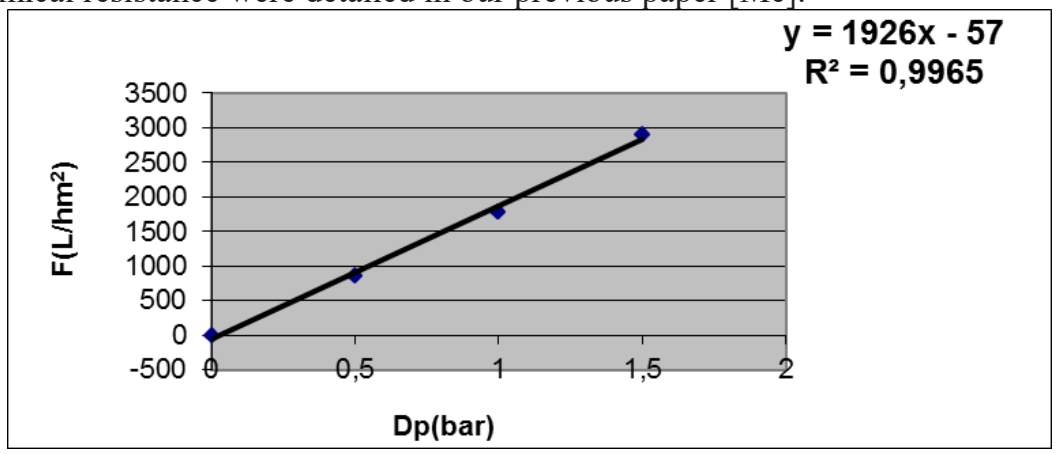

Fig. 6. Water flux versus working pressure.

\subsection{Characterization of the microfiltration layer}

\section{2-1 Scanning electron micrograph and mercury porosimetry}

The morphology, surface quality and thickness of top layer membrane were examined by scanning electron microscopy. Figure 7 shows the cross-section and the surface views of the prepared microfiltration layer; the surface of the top layer is homogenous without defects and microcracks. Moreover, it has a good adherence with the support. Pore size distribution of the top layer measured by mercury porosimetry is centered on $0.19 \mu \mathrm{m}$ that confirms we achieved to prepare a microfiltration layer. 


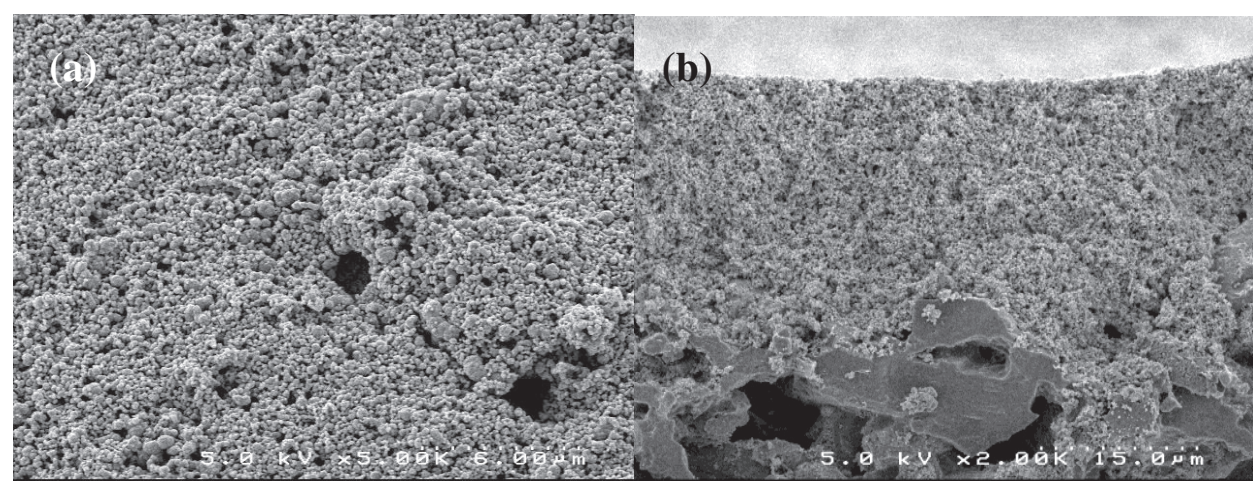

Fig. 7. SEM views of surface (a) and cross-section (b) of zirconia layer.

\section{2-2 Microfiltration tests}

The water flux through the membrane depends on the applied pressure but the stabilization of the flux needs about 1 hour due to formation of a polarization layer. The permeability was determined from the values of flux measured after stabilisation for each working pressure. The curve given the flux vs. pressure is a straight line with a slop equal to about 841 L/h.m2 bar which corresponds to the permeability of the membrane.

\section{2-3 Filtration tests}

Filtrations are performed in the tangential mode to have no deposits on the membranes can cause clogging; the working temperature is kept constant by a cooling by circulating water around the feed tank.

The filtration is carried out without re-circulation of the permeate which results ultimately in accordance with the flow of the membrane used, an increase in the concentration in the feed tray. The concentration of the filtered solution is regarded as constant throughout the filtration. Between each filtration experiment, we systematically perform washing with water under pressure until the flux value at the initial membrane water.

Efficiency of microfiltration process was also tested for the treatment of methylene blue. The results presented in (Figure 8) confirm the possibility to reduce the concentration of the methylene blue by microfiltration treatment.

After a filtration test on a microfiltration membrane, we found that the rejection rate (Figure 8 ) reaches a maximum value of $3.8 \%$ after $40 \mathrm{~min}$. 


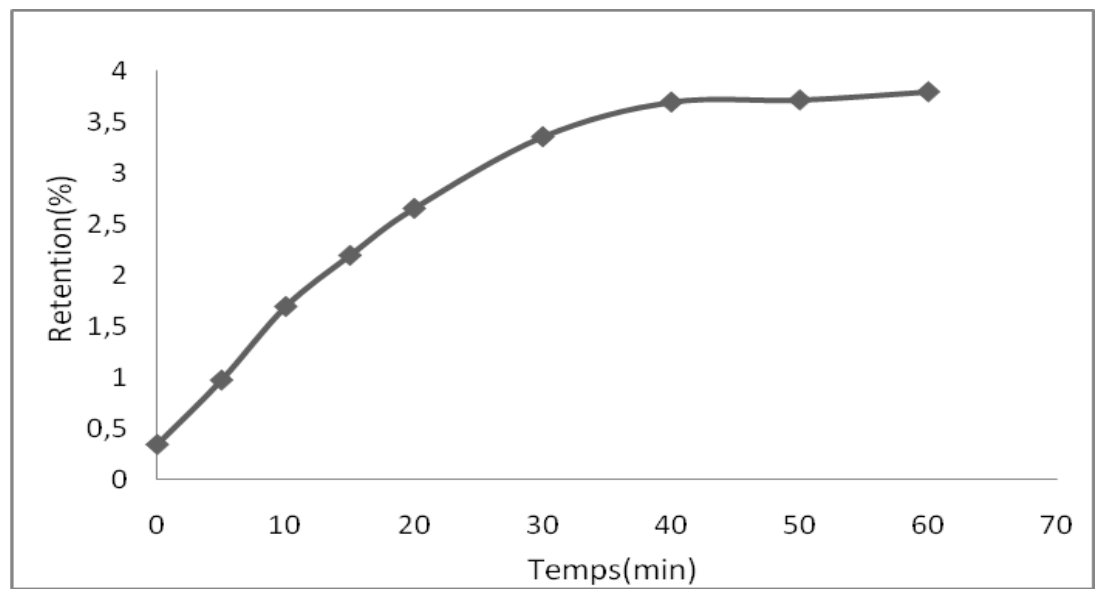

Fig. 8. The rejection rate of methylene blue solution.

\section{Conclusion}

The preparation and characterization of a new microfiltration membrane based on Moroccan clay has been described in this work. The membrane support was prepared by the extrusion of ceramic paste made with Perlite powder. The development of a microfiltration membrane requests a fine grinding of the Perlite powder. The microfiltration layer was deposited on the support by slip casting. The resulting filters present reasonable characteristics of permeability for water.

Notably interesting are the results on retention of methylene blue which allow envisaging these membranes to design a first clarification step of wastewater treatment.

\section{Références}

1. Kosinov N., Gascon J., Kapteijn F., Hensen E.J.M., J. Membr. Sci. 499 (2016) 65.

2. Yeung K.L., Sebastian J.M., Varma A., J. Memb. Sci. 131(1997) 9.

3. Lee S.Y., Lee S.J., Kwon S.J., Yang S.M., Park S.B., J. Memb. Sci. 108 (1995) 97.

4. Nagasawa H., Shigemoto H., Kanezashi M., Yoshioka T., Tsuru T., J. Memb. Sci. 441 (2013) 45.

5. Ahmad A.L., Abdullah Sani N.A., Sharif Zein S.H., Ceram. Int. 37 (2011) 2981.

6. Bouzerara F., Harabi A., Ghouil B., Medjemem N., Boudaira B., Condom S., Procedia Eng. 33 (2012) 278.

7. Elomari H., Achiou B., Ouammou M., Albizane A., Bennazha J., Younsi S.A., El Amrani I., Desal. Water Treat. (2015) 1. 
8. Saffaj N., Persin M., Younsi S.A., Albizane A., Cretin M., Larbot A., Appl. Clay Sci. 31 (2006) 110.

9. Bouazizi A., Saja S., Achiou B., Ouammou M., Calvo J.I., Younsi S.A., Appl. Clay Sci. (2016).

10. Majouli A., Younssi S.A., Tahiri S., Albizane A., Loukili H., Belhaj M., Desal. 277 (2011) 61.

11. N. Saffaj, N. El Baraka, R. Mamouni, H. Zgou, A. Laknifli, S. Alami Younssi, Y. Darman, M. Aboulkacem, O. Mokhtari. New BioCeramic Support Membrane from Animal Bone. j. Micribiol. Biotech. Res, 3 (2013) 1-6.

12. S.Rakib, M Sghyar, M .Rafiq, A Larbot, L. Cot, New porous ceramics for tangential filtration. Sep. Purif. Technol. 25, 385-390, (2001).

13. N.Elmodden, A.Elghazouali, S.Rakib, M.Sghyar, M.Rafiq, A Larbot, L.Cot, Nouveaux supports membranaires à base de chamotte d'argile. Ann.Chim. Sci. Mat. 26, 5-11, (2001).

14. M.R.Weir, E.Rutinduka, C. Dettellier, C.Y.Feng, Q.Wang, T.Matsura, R.LeVan Mao, Fabrication, characterization and preliminary testing of all inorganic ultrafiltration membrane made of a naturally occurring sepiolite clay mineral. J.Membr, (2001).

15. N. El Baraka, N. Saffaj, R. Mamouni, A. Laknifli, S. Alami Younssi, A. Albizane, M. El Haddad, .Elaboration of a new flat membrane support from Moroccan clay. Desalin. Water Treat. 52, (2014) 1357-1361.

16. M.Slansky, Géologie des Phosphates Sédimentaires, Mémoire du BRGM N 114 , (1980).

17. R.A.Young, J.C.Elliot, Atomic-scale bases for several properties of apatites J.Arch.Oral.Biol 11, 699, (1966).

18. 27. Barrouk I., Younssi S.A., Kabbabi A., Persin M., Albizane A., Tahiri S., Desal. Water Treat. 55 (2015) 53. 